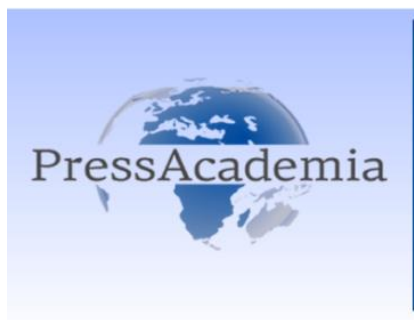

Press Academía

Global Business Research Congress (GBRC), May 24-25, 2017, Istanbul, Turkey

\title{
THE ROLE OF ENVY IN EMPLOYEES ABUSIVE SUPERVISON PERCEPTION AND CONTEXTUAL PERFORMANCE
}

\author{
DOI: 10.17261/Pressacademia.2017.629
}

PAP- GBRC-V.3-2017(55)-p.541-547

\section{Bora Yildiz}

Istanbul University, Faculty of Economics, Department of Business Administration, Beyazit/Istanbul, Turkey. borayildiz@istanbul.edu.tr

\section{To cite this document}

Yıldız, B. (2017). The role of envy in employees abusive supervison perception and contextual performance. PressAcademia Procedia (PAP), V.3, p.541-547.

Permemant link to this document: http://doi.org/10.17261/Pressacademia.2017.629

Copyright: Published by PressAcademia and limited licenced re-use rights only.

\begin{abstract}
The purpose of the study is to filling the gap in the literature by testing the role of employee envy on the abusive supervision perception and contextual performance empirically based on Social Exchange Theory and Victim Precipitation Theory. The study was conducted on the 630 employees from service sector in last quarter of 2016 in Istanbul. Exploratory Factor Analysis with SPSS and Confirmatory factor analysis and structural equation modelling were used to test the data in AMOS. Findings show that envy for others that is one of the sub-dimensions of emploeye envy is a statistically significant and negative predictor of contextual performance, it is also a positive and statistically significant predictor of abusive supervision. On the other hand, it was found that being envy is positive and statistically significant predictor of abusive supervision, while the effect of it is not significant on the contextual performance. The study contributes to understanding the role of negative emotions on employees behaviors and perceptions e.g. contextual performance, abusive supervision.
\end{abstract}

Keywords: abusive supervision, being envy, envy, envy for others, contextual performance.

JEL Codes: M1, M12, M54

\section{KISKANÇLIĞIN ÇALIŞANLARIN ISTiSMARCI YÖNETiM ALGISI VE BAĞLAMSAL PERFORMANS ÜZERINDEKi ROLÜ}

\section{ÖZET}

Bu çalışmanın amacı Mağdur Kaynaklı Suç Teorisi ve Sosyal Mübadele Teorisine dayanarak geliştirilen araştırma modelinin ampirik olarak test edilmesi ile ilgili yazındaki bu boşluğun doldurulmasıdır. Araştırma 2016 yılının son çeyreğinde farklı mesleklerden i̇stanbul'daki 630 hizmet sektörü çalışanı üzerinde yürütülmüştür. Araştırmadan elde edilen veriler SPSS programında açıklayıcı faktör analizi ve AMOS programında doğrulayıcı faktör analizi ve yapısal eşitlik modellemesi kullanılarak test edilmiştir. Araştırma bulguları göstermektedir ki, kıskançlığın alt boyutlarından başkalarını kıskanma boyutu bağlamsal performansın negatif ve istatistiksel açıdan anlamlı bir yordayıcısı iken, istismarcı yönetim algısının ise pozitif ve istatistiksel açıdan anlamlı bir yordayıcısıdır. Diğer yandan kıskançlığın kıskanılmak boyutunun ise yalnızca istismarcı yönetim algısı üzerinde istatistiksel açıdan anlamlı ve pozitif etkileri bulgulanmamıştır. Bu çalışma ile çalışanların bağlamsal performanlarını azaltan ve istismarcı yönetim algılarını arttıran, çalışan temelli değişkenlerden biri olan başkalarını kıskanma boyutunun etkileri ortaya konmuştur.

Anahtar Kelimeler: bağlamsal performans, başkalarını kıskanma, istismarcı yönetim algısı, kıskançlık, kıskanılma.

JEL Kodları: M1, M12, M54 


\section{Giriş}

Gerek günümüz iş dünyasında gerekse geçmişten günümüze uzanan süreçte çalışanların verimi, motivasyonu, iş tatmini ve bunların somut olarak ölçümlendiği iş performansına yönelik pek çok çalışmaya rastlanılmaktadır. Bu çalışmaların birçoğu genellikle örgüt düzeyindeki adalet algısı Devonish ve Greenidge (2010), örgüt kültürü(Wang, Begley, Hui, ve Lee, 2012), etik iklim (Choi, Moon, ve Ko, 2013; Karatepe, 2013), örgütsel destek algısı (Zhong, Wayne, ve Liden, 2016) gibi değişkenlerin bağlamsal performans üzerindeki etkisini incelerken, bir çok araştırma ise negatif bir çalışan algısı olan istismarcı yönetim algısının işten ayrılma niyeti (Haar, de Fluiter, ve Brougham, 2016; Tepper vd. , 2009), sapkın işyeri davranışları (Avey, Wu, ve Holley, 2015), düşük iş tatmini (Hu ve Wang, 2012; Jiang, Wang, ve Lin, 2016; Lian, Ferris, ve Brown, 2012; Mathieu ve Babiak, 2016) düşük örgütsel vatandaşlık davranışları (Gregory, Osmonbekov, Gregory, Albritton, ve Carr, 2013; Liu ve Wang, 2013; Lyu, Zhu, Zhong, ve Hu, 2016; Zellars, Tepper, ve Duffy, 2002) ve düşük çalışan performansı (Jian, Kwan, Qiu, Liu, ve Yim, 2012; Shen, Jing, ve Ma, 2012; Zhou, 2016) gibi negatif etkilerine yoğunlaşmıştır. Ancak her ne kadar yapılan çalışmalar çalışanlardan çok bu değişkenlerin öncülleri olarak örgütsel faktörlere odaklanmış olsa da ilgili yazın incelendiğinde çalışandan kaynaklı öncüllerin incelenmiş olduğu çalışmalar sınırlı düzeydedir. Başka bir söylemle her ne kadar çalışanların kişilik özelliklerinin çeşitli çalışan çıktıları üzerindeki etkileri geçmiş araştırmalarca (Alessandri ve Vecchione, 2012; Hurtz ve Donovan, 2000; Kichuk ve Wiesner, 1997; Salgado, 1998; Ziegler vd. , 2014) incelenmiş olsa da kıskançlık gibi çalışan duygularının bu çıktılar üzerindeki etkilerini inceleyen çalışmalar sınırlı düzeydedir(Kim, O'Neill, ve Cho, 2010; Soo Kyung, Jung, ve Lee, 2013; Tai, Narayanan, ve McAllister, 2012; Robert P Vecchio, 2000; Vecchio, 2005).

Genel olarak iş dünyasındaki kıskançlık duygusunun etkilerine yönelik araştırmaların bulguları karşılaştırıldığında bu duygunun farklı çalışmalarda farklı etkilerinin olduğu ilgili yazındaki çalışmalardan anlaşılmaktadır. Soo Kyung vd. (2013)'ün Amerika'daki otel çalışanları üzerindeki yapmış oldukları çalışmada lider-üye etkileşiminin sapkın işyeri davranışları üzerindeki negatif etkisi bulgulanmıştır. Dahası belirtilen çalışmada başkalarını kıskanma eğilimi ve başkaları tarafından kıskanma duygusuna sahip çalışanların daha fazla sapkın işyeri davranışları sergilediği bulgulanmıştır. Tai vd. (2012) ise kıskançlık kavramının ortaya çıkan sonuçları ile karıştıııldığını ve kıskançlı̆ı bir "sancı, sızı ya da ıstırap (pain)" olarak kavramsallaştırmıştırlar. Daha açık bir ifade ile Tai ve arkadaşları (2012), kıskançlığı başkalarının iyi talihinden duyulan ıstırap ya da acı olarak tanımlayarak kıskançlığın pozitif ya da negatif çıktılarının olabileceğini ifade etmişlerdir. Kim vd. (2010)'nin otel çalışanları üzerinde yapmış oldukları başka bir çalışmada ise lider üye etkileşim algısı düşük çalışanların daha fazla kıskançlık sergilediği, yüksek kıskançlık düzeyine sahip çalışanların daha az örgütsel vatandaşlık davranışı gibi yardım sever davranışlar sergilediği, başka bir söylemle lider-üye etkileşimi algısının düşük olmasının kıskançlığa sebep olduğu dolayısıyla da kıskançlığın daha az örgütsel vatandaşlık davranışları sergilenmesine yol açtığı bulgulanmıştır. Vecchio (2005) ise ilk düzey yöneticiler üzerinde yapmış olduğu araştırmada başkaları tarafından kıskanıımak ile rekabet- ödül boyutu, Makyavelizm ve ay bazındaki uzun ömürlülük arasında pozitif ilişkiler bulgularken, başkalarını kıskanma boyutu ile rekabet-ödül, Makyavelizm, arasında pozitif ilişkiler ve öz benlik, lider-üye etkileşimi ve iş tatmini arasında negatif ilişkiler bulgulamışlardır. Dahası bu çalışmanın bir başka çarpıcı bulgusu ise yüksek düzey makyavelist çalışanların yüksek düzeyde başkaları tarafından kıskanıldığı bulgulanmıştır. Erdil ve Müceldili (2014) ise beyaz yakalı çalışanlar üzerinde yapmış oldukları çalışmada kıskançlık hissinin duygusal adanmışlığı azaltıcı ve işten ayrılma niyeti üzerinde pozitif etkilerinin olduğunu bulgulamıştır.

Bu çalışmada çalışanların kıskançlık duygusunun istismarcı yönetim algısı ve bağlamsal performans üzerindeki etkileri Blau (1964)'nun Sosyal Mübadele Teorisi ve Aquino (2000)' nun Mağdur Kaynaklı Suç Kuramı (Victim Precipitation Theory) dayanarak araştııılmıştır. İlgili yazın incelendiğinde istismarcı yönetim algısı ve bağlamsal performansın öncüllerini belirlemeye yönelik pek çok çalışma yapılmasına rağmen özellikle negatif bir duygu olarak kabul edilen kıskançlık duygusunun çalışan performansı ve istismarcı yönetim algısı üzerindeki etkilerini inceleyen çalışmalar sınırlı düzey dedir. Bu bağlamada araştırma kapsamında cevaplanması amaçlanan araştırma sorusu şöyledir: Çalışanların kıskançlık duygusu istismarcı yönetim algısı ve bağlamsal performansın bir öncülü müdür?

Yukarıdaki açıklamalar ışığı altında araştırma şu başlıklar altında sunulmaktadır: öncelikle kıskançlık değişkenine iliş̧in tanımlayıcı bilgiler sunularak bu yapı ile ilgili yazındaki çalışmaların bulgularından bahsedilecektir. Ardından istismarcı yönetim algısı ve bağlamsal performans değişkenlerine ilişkin bilgiler sunularak bu değişkenler ve kıskançlık arasındaki ilişkilerden bahsedilecektir. Ardından veri ve yöntemden bahsedilerek, bulgular, tartışma ve sonuçlar başlığı altında araştırma sonuçları sunulacaktır.

\section{LITERATÜR INCELEMESi}

Sosyal Mübadele Teorisi (Social Exchange Theory) (Blau, 1964) çalışanların çeşitli maddi ve maddi olmayan unsurları birbirleri arasında mübadele ettiğini ileri sürmektedir. Buna göre çalışanların çeşitli algı, tutum ve davranışları çalışanların bu unsurlara göre davrandığını ya da aynı şekilde cevap verdiğini önermektedir. Daha açık bir ifadeyle pozitif yönde algıları olan çalışanların pozitif tutum ve davranışsal niyetler sergileyebileceği dolayısıyla da pozitif davranışlar sergileyebileceği teori tarafından öngörülmektedir. Ayrıca, bu ilişkinin tem tersi negatif algı, tutum, davranış ve buna benzer davranışsal niyetler açısından geçerlidir. Sosyal mübadele teorisi bağlamında düşünüldüğünde kıskançlığın negatif sonuçlar ortaya çıkaran, çalışanların örgüt içerisindeki bilgi ve birikimlerini paylaşmaktan kaçınmasını sağlayan, iş ortamındaki arkadaşlık ilişkilerini baltalayan (Erdil ve Müceldili, 2014) ve dolayısıyla işletme içerisindeki çalışanların rol ötesi davranışlar sergilemesini engelleyen bir negatif duygu değişkeni olduğu söylenebilir. Diğer yandan Mağdur Kaynaklı Suç Kuramı (Victim Precipitation Theory) (Aquino, 2000) açısından düşünüldüğünde ise kıskanç kişilerin negatif doğalarından dolayı yöneticilerinin normal davranışlarını diğer iş arkadaşları ile kıyaslandığında daha fazla istismarcı olarak algılayabilecekleri öngörülmektedir. Başka bir söylemle Mağdur Kaynaklı Suç Kuramı iş yerindeki çeşitli olumsuz algıların bizzat kişinin kendisinden kaynaklandığını her zaman çalışan dışındaki faktörlerin olumsuz olmadığını çalışanın da etraftaki olum olabilecek durumları olumsuz algılamaya daha yatkın olduğunu ileri sürmektedir. Nitekim, Sezici ve Yıldız (2017)'ın yapmış oldukları çalışmada 
nevrotik kişilik özelliği ile istismarcı yönetim algısı arasında istatistiksel açıdan anlamlı ve pozitif ilişkiler bulgulanmıştır. Bu bulgu ve teorik dayanaklara binaen bu çalışmada kıskançlığın olumlu bir davranışsal değişken olan bağlamsal performans ile olumsuz bir çalışan algısı olan istismarcı yönetim algısı üzerindeki direk etkileri araştırılmıştır.

Çalışan kıskançlığı işletmelerde oldukça yaygın olan bir duygudur (Tai vd. , 2012). Vecchio (2005) çalışan kıskançlığını çalışanın iş yerindeki sosyal duruşuna yönelik bir tehdit ya da kaybetme korkusu olarak tanımlamaktadır. Çalışan kıskançlığı farklı araştırmalarca bir düşünceler, duygular ve başkalarının elde ettikleri arzulanan şeylerden ortaya çıkan davranış biçimi olarak tanımlanmaktadır (Dogan ve Vecchio, 2001; Vecchio, 1997a, 1997b, 2000; Vecchio, 2005). Buna ek olarak Vecchio (2005) çalışan kıskançlığını kıskanılmak ve başkalarını kıskanmak olarak iki boyuttan oluştuğunu ifade etmektedir. Diğer yandan Erdil ve Müceldili (2014) ise kıskançlığı olumsuz bir duygu olarak ifade etmektedir. Benzer şekilde belirtilen çalışmada kıskançlığın pozitif çıktılarının olabileceği de vurgulanmaktadır. Ancak bu çalışmada önceki çalışmalarla paralel olarak çalışan kıskançlığı daha çok negatif çıktılar ile ilişkili olan negatif bir duygu değişkeni olarak ele alınmıştır.

Diğer yandan istismarcı yönetim ise Tepper (2000) tarafından astın yöneticisine yönelik fiziksel kontak dışındaki sözlü ve sözlü olmayan ve süreklilik arz eden zorba davranışlarına yönelik algısı olarak tanımlanmaktadır. İstismarcı yönetim algısının çeşitli değişkenler üzerindeki negatif etkilerini ölçmeye yönelik çalışmalar ilgili yazında bolca mevcuttur. Örneğin Tepper, Duffy, Hoobler, ve Ensley (2004) yapmış oldukları çalışmada istismarcı yönetim algısının iş arkadaşlarının örgütsel vatandaşıı davranışları, iş tatmini ve örgütsel bağılıı ile negatif yönde ilişkili olduğu bulgulanmıştır. Tepper, Duffy, ve Shaw (2001) ise istismarcı yönetim algısının fonksiyonel olmayan direnç üzerindeki etkisinin sorumlu kişilik özelliği ve uyumluluk düzeyi düşük olan çalışanlarda daha fazla olduğunu bulgulamıştır. Buna ek olarak Sezici ve Yıldız (2017) ise istismarcı yönetim algısına çalışanların nevrotik kişilik özelliğine sahip olmasının sebep olduğunu dolayısıyla da bu durumun tükenmişliğin boyutlarından biri olan kişisel başarı hissinde azalmaya neden olduğunu bulgulamıştır. Tanımdan anlaşılacağı üzere bu algı bir anlamda çalışanın yöneticisine yönelik subjektif bir değerlendirme niteliğindedir (Tepper, 2000). Başka bir anlatımla yöneticinin istismarcı yönetim uygulayıp uygulamadığı bir anlamda astın kişisel değerlendirmesi ile ortaya çıkmaktadır. Bu bağlamda farklı bireylerin farklı koşullar altındaki istismarcı yönetim algılarının gerek durumsal gerekse kişilik özelliklerine göre değişebildiği söylenebilir. Bu bağlamda kıskanç olan çalışanların yöneticilerini kıskanç olarak algılama potansiyellerinin daha fazla olacağı ön görülmektedir. Buna göre mağdur kaynaklı suç kuramına dayanarak geliştirilen araştırmanın birinci hipotezi şöyledir:

Hipotez 1a: Kıskanılmak duygusu ile çalışanların istismarcı yönetim algıları arasında pozitif yönlü bir ilişki vardır.

Hipotez 1b: Başkalarını kıskanma duygusu ile çalışanların istismarcı yönetim algıları arasında pozitif yönlü bir ilişki vardır.

Örgütlerin çalışanlardan beklemiş olduğu ya da artmasını istemiş olduğu davranışlardan biri de bağlamsal performanstır. Her ne kadar ilk başlarda performans genel bir kavram olarak yönetim literatüründe yer almış olsa da Motowidlo ve Van Scotter (1994) hava kuvvetleri personeli üzerinde yapmış oldukları çalışmada performansın görev performansı ve bağlamsal performans olmak üzere genelden ziyade çok boyutlu bir yapı sergilediğini ortaya koymuşlardır. Çalışanların sadece iş tanımları ve iş gereklerinde belirtilen kriterler neticesinde işe alınmalarıyla kendilerinden beklenen ve gözlenmesi kolay olan performans ölçütleri ilgili yazında görev performansı olarak tanımlanmaktadır (Borman ve Motowidlo, 1993). Diğer yandan aynı çalışmada özellikle personel seçme araştırma ve faaliyetlerinde görev performansının sağlanmasını kolaylaştırıcı olarak kabul edilen yardım severlik, gönüllülük, kurallara uymak, örgütsel hedef ve amaçları desteklemek gibi bazı aktivitelerin gözden kaçtığı ya da değerlendirilmeye alınmadığını ifade edilmektedir. Borman ve Motowidlo (1993) sosyal, psikolojik ve örgütsel çevreyi destekleyen bu davranışları "bağlamsal performans" olarak tanımlamaktadır.

Bağlamsal performans ile ilgili yazın incelendiğinde bağlamsal performansın öcüllerini belirlemeye yönelik ve bağlamsal performansın örgütlerin performansı üzerindeki etkilerini incelemeye yönelik pek çok çalışmaya rastlanılmaktadır (Cichy, Cha, ve Kim, 2009; Devonish ve Greenidge, 2010; Guthridge ve Wearing, 2003; Ocel, 2013; Wang vd. , 2012; Yousaf, Yang, ve Sanders, 2015). Bu araştırmaların sonuçları incelendiğinde genellikle kişi-örgüt uyumunun, algılanan örgütsel desteğin, algılanan etik iklimin, algılanan örgütsek adaletin ve içsel motivasyon düzeyinin yüksek olduğu durumlarda çalışanların bağlamsal performanslarında istatistiksel açıdan anlamlı düzeyde artışların olduğu söylenebilir. Kişilik ile ilgili yapılan çalışmalarda ise spesifik kişilik özelliklerine sahip çalışanların farklı düzeylerde bağlamsal performans sergiledikleri bulgulanmıştır. (Judge, LePine, ve Rich, 2006; Wang vd. , 2012). Örneğin Judge vd. (2006) yapmış oldukları çalışmada narsist kişilik özelliğine sahip çalışanların daha fazla bağlamsal performans sergilediğini bulgulamıştır. Benzer şekilde Wang vd. (2012) ise sorumluluk kişilik özelliğinin bağlamsal performans üzerinde pozitif yönde etili olduğunu inovatif ve çıktı eğilimli kültürler bağlamında bulgulamıştır. Lam, Huang, Walter, ve Chan (2016) Yapmış oldukları çalışmada negatif bir duygu değişkeni olan kıskançlığın iş performansı ile negatif yönde ilişkili olduğunu bulgulanmıştır. Tai vd. (2012) ise yapmış oldukları kavramsal çalışmada öz kendini değerlendirmesi yüksek olan çalışanlarda kıskançlığın olumlu sosyal davranışlar ve iş performansı ile pozitif, sosyal baltalama davranışları ile negatif yönde ilişkili olabileceğini önermiştir. Benzer şekilde aynı çalışmada bireyin yetkin ve diğer iş arkadaşlarına olan ılımlılığı da önemli faktörler olarak gözükmektedir. Başka bir söylemle sadece yetkin olan ancak arkadaşlarına karşı ııımlı olmayan çalışanların daha fazla baltalama davranışlarına meyilli olabilecekleri teorik bağlamda öngörülmüştür. Yukarıdaki çalışmalar ve teorik dayanaklar bağlamında bu çalışmada kıskançlık duygusunun negatif bir duygu olarak ele alındığı düşünüldügünnde Sosyal Mübadele Kuramına dayanarak geliştirilen araştırmanın ikinci hipotezi şöyledir:

Hipotez 2a: Kıskanılmak duygusu ile çalışanların bağlamsal performansları arasında negatif yönlü bir ilişki vardır.

Hipotez 2b: Kıskanılmak duygusu ile çalışanların bağlamsal performansları arasında negatif yönlü bir ilişki vardır. 
Şekil 1: Kavramsal Model

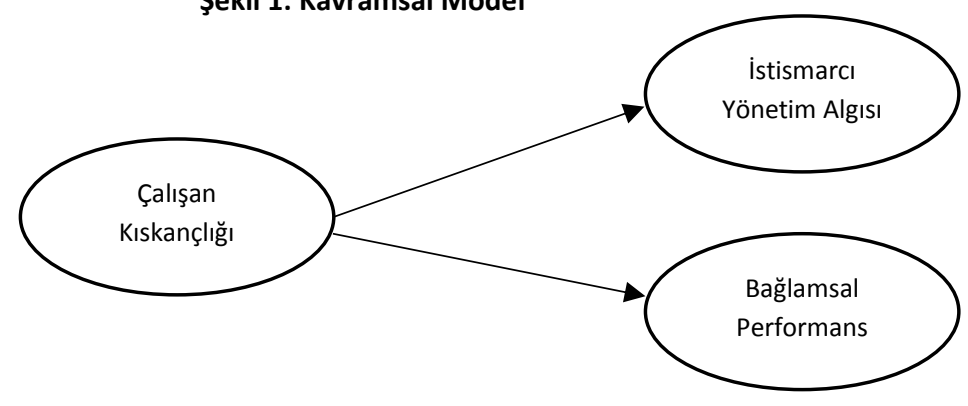

\section{VERI VE YÖNTEM}

Araştırma 2016 yılının son çeyreğinde farklı mesleklerden İstanbul'daki kolayda örnekleme yöntemi ile ulaşılan 630 hizmet sektörü çalışanı üzerinde yürütülmüştür. Araştırmada veri toplama amacıyla anket tekniğinden yararlanılmıştır. Kullanılan anket formu iki bölümden oluşmaktadır; ilk bölümde katılımcıların yaş, cinsiyet, medeni durum, kıdem, eğitim durumu, deneyim ve sektörleri hakkında bilgi toplamaya yönelik kategorik değişkenler yer alırken ikinci bölümde ise istismarcı yönetim algısı, kıskançlık ve bağlamsal performansı ölçmeye yönelik güvenilirlik ve geçerlilik çalışmaları önceki araştırmalarca yapılmış olan ölçekler kullanılmıştır.

Kıskançlık değişkenini ölçmek amacıyla Vecchio (2005) tarafından geliştirilen ve 8 ifadeden (2 boyut; kıskanılmak (4 ifade) başkalarını kıskanma (4 ifade)) oluşan çalışan kıskançlığı ölçeği kullanıımıştır (örnek ifade; Bazen yöneticimle olan yakın iş ilişkilerim yüzünden iş arkadaşlarım tarafından kıskanılırım (kıskanılmak boyutu), Bir şekilde birilerinin tamamen şans eseri olarak en iyi pozisyonlara atandığını görmek beni sinirlendirir( başkalarını kıskanma boyutu) (1= Hiç Katılmıyorum; $5=$ Tamamen Katılıyorum). İstismarcı yönetim algısı Motowidlo ve Van Scotter (1994) tarafından geliştirilen ve 15 ifadeden oluşan istismarcı yönetim algısı ölçeği ile ölçülmüştür (örnek ifade; Yöneticim kendisinden kaynaklanan problemlerden beni sorumlu tutar) (1= Hiçbir zaman; $5=$ Her zaman). Bağlamsal performans Borman ve Motowidlo (1993) tarafından geliştirilen 16 ifadeli bağlamsal performans ölçeği ile ölçülmüştür (örnek ifade; Yönetim tarafından onaylanmayan yöntemlerden kaçınır, kurallara uyarım) (1= Hiçbir zaman; $5=$ Her zaman).

Araştırmaya katılan kişilerin demografik profilleri incelendiğinde kadınların \%48.9'u (308 kişi) erkeklerin ise \%51.1'i (322 kişi) oluşturduğu gözlenmektedir. Yaş bakımından ise büyük bir çoğunluğun (\%31.3) 18-25 yaş aralığında olduğu dikkat çekmektedir. Yine araştırmaya katılanların sektörel dağılımları incelendiğinde büyük bir çoğunluğun (\%76.2) kamu sektörü çalışanları olduğu gözlenmektedir. Kıdem değişkeni açısından incelendiğinde ise büyük bir çoğunluğun (\%67.5), 1-5 yıllık kıdeme sahip olduğu, 11-15 yıllık deneyime sahip olduğu (\%51.4) gözlenmiştir. Diğer yandan araştırmadan elde edilen veriler öncelikle SPSS programında açıklayıcı faktör analizinde test edilmiş, akabinde ise AMOS programında doğrulayııı faktör analizi ve yapısal eşitlik modellemesi kullanılarak test edilmiştir.

\section{BULGULAR VE TARTIŞMA}

Araştırmada kullanılan ölçeklerin yapı geçerliliği için değişkenler açıklayıcı faktör analizi ile test edilmiş, tüm boyutların varyansın \%57.23'lük kısmını açıkladığı gözlenmiştir (KMO=.864; $x 2=5103.770 ; \mathrm{df}=210 ; \mathrm{p}<0.001)$. Açıklayıcı faktör analizi indekslerine bakıldığında verinin sonraki analizler için ve örneklem yeterliliği açısından açıklayıcı faktör analizi için yeterli olduğu söylenebilir (Hair, Anderson, Babin, ve Black, 2010). Buna göre istismarcı yönetim algısı toplam açıklanan varyansın \%23.38'ini, bağlamsal performans \%14.49'unu, kıskanılmak \%11.96'sını ve son olarak başkalarını kıskanmak \%7.42'sini açıklamaktadır. Ölçeklerin Cronbach Alpha (Cronbach, 1951) değerleri sırasıyla $\alpha=.89, \alpha=.83, \alpha=.89, \alpha=.67$ 'dir. Her ne kadar başkalarını kıskanma boyutu Cronbach (1951) tarafından önerilen $\alpha=.70$ değerinden düşük olsa da bu değer Nunnally (1967) tarafından belirtilen $\alpha=.65-.70$ aralığında olduğundan güvenilirlik seviyesini kabul edilebilir sınırlar içerisinde olduğu söylenebilir.

Tablo 1: Deişkenler Arası Tanımlayıcı İstatistikler ve Korelayon Değerleri

\begin{tabular}{|c|c|c|c|c|c|c|}
\hline Değişkenler & Ort. & Std. Sapma & 1 & 2 & 3 & 4 \\
\hline İstismarcı Yönetim Algısı & 1.51 & .581 & $(\alpha=.89)$ & & & \\
\hline Bağlamsal Performans & 3.72 & .792 & $-.106 * *$ & $(\alpha=.83)$ & & \\
\hline Kıskanılmak & 2.86 & 1.037 & $.193^{* *}$ & .008 & $(\alpha=.89)$ & \\
\hline Başkalarını Kıskanmak & 2.16 & .710 & $.300 * *$ & $-.186 * *$ & .050 & $(\alpha=.67)$ \\
\hline
\end{tabular}

*Korelasyon $\mathrm{p}<0,05$ anlamlılık düzeyinde anlamlıdır; ** Korelasyon $\mathrm{p}<0,01$ anlamlılık düzeyinde anlamlıdır; İçsel tutarlılık düzeyleri (Cronbach's Alpha ) parantez içinde sunulmuştur.

Diğer yandan yapılan doğrulayıcı faktör analizi neticesindeki ulaşılan model fit değerlerinin CMIN/DF=2.682; GFI=.93; NFI=.91; $\mathrm{CFI}=.94$; RMSEA $=.052$ olduğu gözlenmiştir. Elde edilen model fit değerleri göz önüne alındığında modelin fit olduğu söylenebilir (Gaskin ve Lim, 2016; Hu ve Bentler, 1999). 
Yapısal eşitlik modellemesi ile yapılan yol analizi göstermektedir ki, kıskançlığın alt boyutlarından kıskanılmak $(\beta=.189 ; p<0.001)$ ve başkalarını kıskanma ( $\beta=.429 ; p<0.001)$ boyutu istismarcı yönetim algısının istatistiksel açıdan pozitif ve anlamlı yordayıcılarıdır. Diğer yandan yine kıskançlık duygusunun kıskanılmak boyutunun bağlamsal performans üzerinde istatistiksel açıdan anlamlı bir etkisi bulunmaz iken ( $\beta=.035 ; p=.443$ ), başkalarını kıskanma boyutunun ise bağlamsal performans üzerinde istatistiksel açıdan anlamlı ve pozitif bir etkisinin olduğu bulgulanmıştır $(\beta=-.313 ; p<0.001)$. Model uyum indekslerine bakıldığında ise tüm değerlerin kabul edilebilir uyum aralıklarında olduğu söylenebilir (CMIN/DF=2.671; GFI=.93; NFI=.91; CFI=.94; RMSEA=.052) (Gaskin ve Lim, 2016; Hu ve Bentler, 1999). Sonuçlar değerlendirildiğinde $\mathrm{H} 1 \mathrm{a}, \mathrm{H} 1 \mathrm{~b}$ ve $\mathrm{H} 2 \mathrm{~b}$ hipotezleri desteklenirken $\mathrm{H} 2 \mathrm{a}$ hipotezi ise desteklenmemiştir.

\section{SONUÇ}

Çalışma kapsamında incelenen değişkenler arasındaki ilişkilerin negatif bir duygu değişkeni olan çalışan kıskançlı̆̆ı yazınına katkıda bulunacağı, gelecek deneysel ve kavramsal çalışmalara yön vereceği düşünülmektedir. Özellikle ulusal ve uluslararası yazındaki çalışmaların sınırlılı̆̆ı, konuya olan ilginin geleceğe yönelik devam edeceği beklentisi ve yapılacak olan çalışmaların çalışanların karmaşık doğasını daha iyi anlamada katkı sağlayacağı düşünüldüğünde konunun önemi daha net anlaşımaktadır. Çalışmanın teorik bağlamdaki katkısı gerek sosyal mübadele teorisi gerekse mağdur kaynaklı suç kuramı ile araştırma sonuçlarının desteklenmesi ile beraber çalışan kıskançlığının hem rol ötesi davranışlardan biri olan bağlamsal performansı azaltıcı hem de negatif bir çalışan algısı olan istismarcı yönetim algısını arttırıcı bir yapıya sahip olduğunun anlaşılmasıdır. Diğer yandan araştırmanın iş dünyasındaki uygulamalara katkısı ise şu şekilde sıralanabilir: Özellikle personel tedarik, seçme ve yerleştirme faaliyetlerinde hayati öneme sahip olan doğru kişilerin doğru işe yerleştirilmesinin sağlanmasında çalışanların sadece kişilik özelliklerinin değil, aynı zamanda duygularını ölçmeye yönelik test ve seçme uygulamalarının da kullanılmasın daha doğru bir işgören temin sürecinin gerçekleşmesine katkıda bulunacağı düşünülmektedir. İşletmeler için bağlamsal performansın önemi ve geçmiş araştırmaların sonuçları göz önüne alındığında bu tip rol ötesi davranışları baltalayan negatif öncüllerin olabildiğince minimize edilmesi işletmelerin genel performansının artması yönünde katkı sağlayacağı düşünülmektedir. Diğer yandan negatif bir çalışan algısı olan istismarcı yönetim algısının her zaman yöneticilerden kaynaklanamayacağı bazen çalışanların kıskançlık gibi negatif duygulara sahip olmasında da kaynaklanabileceği söylenebilir. Buna göre örgütler bünyelerinde bulanan çalışanların kıskançlık duygularını efektif bir şekilde yönetecek, minimize edecek önlem ve faaliyetler ile çaba göstermelidirler.

\section{KAYNAKLAR}

Alessandri, G., \& Vecchione, M. (2012). The higher-order factors of the Big Five as predictors of job performance. Personality and Individual Differences, 53(6), 779-784.

Aquino, K. (2000). Structural and individual determinants of workplace victimization: The effects of hierarchical status and conflict management style. Journal of Management, 26(2), 171-193.

Avey, J. B., Wu, K., \& Holley, E. (2015). The Influence of Abusive Supervision and Job Embeddedness on Citizenship and Deviance. Journal of Business Ethics, 129(3), 721-731.

Blau, P. M. (1964). Exchange and power in social life: Transaction Publishers.

Borman, W. C., \& Motowidlo, S. M. (1993). Expanding the criterion domain to include elements of contextual performance. In N. Schmitt \& W. C. Borman (Eds.), Personnel selection in organizations (pp. 71-98). San Francisco: Jossey-Bass.

Choi, B. K., Moon, H. K., \& Ko, W. (2013). An organization's ethical climate, innovation, and performance Effects of support for innovation and performance evaluation. Management Decision, 51(6), 1250-1275.

Cichy, R. F., Cha, J., \& Kim, S. (2009). The relationship between organizational commitment and contextual performance among private club leaders. International Journal of Hospitality Management, 28(1), 53-62.

Cronbach, L. J. (1951). Coefficient alpha and the internal structure of tests. psychometrika, 16(3), 297-334.

Devonish, D., \& Greenidge, D. (2010). The Effect of Organizational Justice on Contextual Performance, Counterproductive Work Behaviors, and Task Performance: Investigating the moderating role of ability-based emotional intelligence. International Journal of Selection and Assessment, 18(1), 7586.

Dogan, K., \& Vecchio, R. P. (2001). Managing envy and jealousy in the workplace. Compensation \& Benefits Review, 33(2), 57-64.

Erdil, O., \& Müceldili, B. (2014). The effects of envy on job engagement and turnover intention. Paper presented at the Procedia-Social and Behavioral Sciences.

Gaskin, J., \& Lim, J. (2016). Model Fit Measures, AMOS Plugin, Gaskination's StatWiki.

Gregory, B. T., Osmonbekov, T., Gregory, S. T., Albritton, M. D., \& Carr, J. C. (2013). Abusive supervision and citizenship behaviors: exploring boundary conditions. Journal of Managerial Psychology, 28(6), 628-644.

Guthridge, M. D., \& Wearing, A. J. (2003). Leadership, psychological climate, service climate, and contextual performance in health care. Australian Journal of Psychology, 55, 126-126. 
Haar, J. M., de Fluiter, A., \& Brougham, D. (2016). Abusive supervision and turnover intentions: The mediating role of perceived organisational support. Journal of Management \& Organization, 22(2), 139-153.

Hair, J. F., Anderson, R. E., Babin, B. J., \& Black, W. C. (2010). Multivariate data analysis: A global perspective (Vol. 7): Pearson Upper Saddle River, NJ.

Hu, C. Y., \& Wang, L. (2012). How abusive supervision affect job satisfaction? A moderated mediation model. International Journal of Psychology, 47, 537-537.

Hu, L. t., \& Bentler, P. M. (1999). Cutoff criteria for fit indexes in covariance structure analysis: Conventional criteria versus new alternatives. Structural Equation Modeling: A Multidisciplinary Journal, 6(1), 1-55. doi:10.1080/10705519909540118

Hurtz, G. M., \& Donovan, J. J. (2000). Personality and job performance: The big five revisited. Journal of Applied Psychology, 85(6), 869-879.

Jian, Z. Q., Kwan, H. K., Qiu, Q., Liu, Z. Q., \& Yim, F. H. K. (2012). Abusive supervision and frontline employees' service performance. Service Industries Journal, 32(5), 683-698.

Jiang, W., Wang, L. L., \& Lin, H. (2016). The role of cognitive processes and individual differences in the relationship between abusive supervision and employee career satisfaction. Personality and Individual Differences, 99, 155-160.

Judge, T. A., LePine, J. A., \& Rich, B. L. (2006). Loving yourself abundantly: Relationship of the narcissistic personality to self- and other perceptions of workplace deviance, leadership, and task and contextual performance. Journal of Applied Psychology, 91(4), 762-776.

Karatepe, O. M. (2013). Inking Perceived Ethical Climate to Performance Outcomes: The Mediating Role of Job Embeddedness. Ekonomska Istrazivanja-Economic Research, 26(4), 77-90.

Kichuk, S. L., \& Wiesner, W. H. (1997). The Big Five personality factors and team performance: implications for selecting successful product design teams. Journal of Engineering and Technology Management, 14(3-4), 195-221.

Kim, S., O'Neill, J. W., \& Cho, H. M. (2010). When does an employee not help coworkers? The effect of leader-member exchange on employee envy and organizational citizenship behavior. International Journal of Hospitality Management, 29(3), 530-537.

Lam, C. K., Huang, X., Walter, F., \& Chan, S. C. H. (2016). Coworkers' Relationship Quality and Interpersonal Emotions in Team-Member Dyads in China: The Moderating Role of Cooperative Team Goals. Management and Organization Review, 12(4), 687-716.

Lian, H. W., Ferris, D. L., \& Brown, D. J. (2012). Does taking the good with the bad make things worse? How abusive supervision and leader-member exchange interact to impact need satisfaction and organizational deviance. Organizational behavior and human decision processes, $117(1), 41-52$.

Liu, X. Y., \& Wang, J. (2013). Abusive supervision and organizational citizenship behaviour: is supervisor-subordinate guanxi a mediator? International Journal of Human Resource Management, 24(7), 1471-1489.

Lyu, Y. J., Zhu, H., Zhong, H. J., \& Hu, L. Q. (2016). Abusive supervision and customer-oriented organizational citizenship behavior: The roles of hostile attribution bias and work engagement. International Journal of Hospitality Management, 53, 69-80.

Mathieu, C., \& Babiak, P. (2016). Corporate psychopathy and abusive supervision: Their influence on employees' job satisfaction and turnover intentions. Personality and Individual Differences, 91, 102-106.

Motowidlo, S. J., \& Van Scotter, J. R. (1994). Evidence that task performance should be distinguished from contextual performance. Journal of Applied Psychology, 79(4), 475.

Nunnally, J. C. (1967). Psychometric theory.

Ocel, H. (2013). The Relationships of Contextual Performance with Person-Organization Fit, Perceived Organizational Prestige and Organizational Identity Strength: The Mediating Role of Organizational Commitment. Turk Psikoloji Dergisi, 28(71), 37-56.

Salgado, J. F. (1998). Big Five personality dimensions and job performance in army and civil occupations: A European perspective. Human Performance, 11(2-3), 271-288.

Sezici, E., \& Yıldız, B. (2017). Nevrotik Kişilik Özelliği ile Kişisel Başarı Hissinde Azalma İlişkisinde İstismarcı Yönetimin Aracılık Etkisi. Yakın Doğu Üniversitesi Sosyal Bilimler Dergisi, X(2), forthcoming.

Shen, C. G., Jing, Y., \& Ma, H. Y. (2012). Abusive supervision and employee performance: mechanism of fsb and learning goal orientation. International Journal of Psychology, 47, 519-519.

Soo Kyung, K., Jung, D. I., \& Lee, J. S. (2013). Service employees' deviant behaviors and leader-member exchange in contexts of dispositional envy and dispositional jealousy. Service Business, 7(4), 583-602.

Tai, K., Narayanan, J., \& McAllister, D. J. (2012). Envy as Pain: Rethinking the Nature of Envy and Its Implications for Employees and Organizations. Academy of Management Review, 37(1), 107-129.

Tepper, B. J. (2000). Consequences of abusive supervision. Academy of Management Journal, 43(2), 178-190.

Tepper, B. J., Carr, J. C., Breaux, D. M., Geider, S., Hu, C. Y., \& Hua, W. (2009). Abusive supervision, intentions to quit, and employees' workplace deviance: A power/dependence analysis. Organizational behavior and human decision processes, 109(2), $156-167$.

Tepper, B. J., Duffy, M. K., Hoobler, J., \& Ensley, M. D. (2004). Moderators of the relationships between coworkers' organizational citizenship behavior and fellow employees' attitudes. Journal of Applied Psychology, 89(3), 455-465. 
Tepper, B. J., Duffy, M. K., \& Shaw, J. D. (2001). Personality moderators of the relationship between abusive supervision and subordinates' resistance. Journal of Applied Psychology, 86(5), 974-983.

Vecchio, R. (2005). Explorations in employee envy: Feeling envious and feeling envied. Cognition \& Emotion, 19(1), 69-81.

Vecchio, R. P. (1997a). Categorizing coping responses for envy: A multidimensional analysis of workplace perceptions. Psychological reports, 81(1), 137-138.

Vecchio, R. P. (1997b). It's not easy being green: Jealousy and envy in the workplace.

Vecchio, R. P. (2000). Negative emotion in the workplace: Employee jealousy and envy. International Journal of Stress Management, 7(3), 161-179.

Wang, H., Begley, T., Hui, C., \& Lee, C. (2012). Are the effects of conscientiousness on contextual and innovative performance context specific? Organizational culture as a moderator. International Journal of Human Resource Management, 23(1), 174-189.

Yousaf, A., Yang, H. D., \& Sanders, K. (2015). Effects of intrinsic and extrinsic motivation on task and contextual performance of Pakistani professionals The mediating role of commitment foci. Journal of Managerial Psychology, 30(2), 133-150.

Zellars, K. L., Tepper, B. J., \& Duffy, M. K. (2002). Abusive supervision and subordinates' organizational citizenship behavior. Journal of Applied Psychology, 87(6), 1068-1076.

Zhong, L. F., Wayne, S. J., \& Liden, R. C. (2016). Job engagement, perceived organizational support, high-performance human resource practices, and cultural value orientations: A cross-level investigation. Journal of Organizational Behavior, 37(6), 823-844.

Zhou, L. (2016). Abusive Supervision and Work Performance: The Moderating Role of Abusive Supervision Variability. Social Behavior and Personality, 44(7), 1089-1098.

Ziegler, M., Bensch, D., Maass, U., Schult, V., Vogel, M., \& Buhner, M. (2014). Big Five facets as predictor of job training performance: The role of specific job demands. Learning and Individual Differences, 29, 1-7. 